\title{
The Effect of Vocabulary Flooding Technique on Iranian EFL Elementary Learners' Vocabulary Learning
}

\author{
Touran Ahour (Corresponding author) \\ Department of English, Tabriz Branch, Islamic Azad University, Tabriz, Iran \\ E-mails: ahour@iaut.ac.ir; touranahour@yahoo.com \\ Nima Pajoman \\ Department of English, Tabriz Branch, Islamic Azad University, Tabriz, Iran \\ E-mail: nimapajoman@ymail.com \\ Nasrin Hadidi Tamjid \\ Department of English, Tabriz Branch, Islamic Azad University, Tabriz, Iran \\ E-mail:nhadidi@iaut.ac.ir
}

Received: 04-08-2013

Accepted: 08-09-2013

Published: 01-11-2013

doi:10.7575/aiac.ijalel.v.2n.6p.185

URL: http://dx.doi.org/10.7575/aiac.ijalel.v.2n.6p.185

\begin{abstract}
The aim of this study was to find out the effect of using vocabulary flooding technique on Iranian EFL elementary learners' vocabulary learning at the recognition level. A pretest-posttest control group design was used in this quasiexperimental research. The study was conducted at a secondary school in Sahand, a city located in the East-Azerbaijan province in Iran. Four intact grade-three classes were considered for the study. A KET test was administered and based on its results, two classes were selected as the homogenous ones, which were randomly assigned into the vocabulary flooding (experimental) and no vocabulary flooding (control) groups, each with 30 students. After the vocabulary recognition pretest, supplementary vocabulary teaching was used as the treatment in both groups. In the Experimental group, the target words were presented and practiced in flooding form, that is, in six or more sentences, while in the Control group, students were taught and practiced in only one sentence. After the treatment, two posttests (immediate and delayed) were conducted in both groups. The results of the One-way within-subjects and between-subjects Repeated-Measures ANOVA revealed that there were statistically significant differences within and between the experimental and control groups in the three vocabulary recognition tests. It was found that the participants' receptive vocabulary knowledge was improved in the experimental group as a result of using vocabulary flooding technique. The implications are provided for the syllabus designers, textbook writers and EFL teachers.
\end{abstract}

Keywords: Input flood, vocabulary flooding, vocabulary recognition, elementary learners, EFL, ESL

\section{Introduction}

Language learning is considered to be a complex process because it seems to involve learning of many subcomponents such as vocabulary and structure. Decarrio (2001) declares the centrality of vocabulary learning to language acquisition in first, second, or foreign language learning. For Rivers (1981), learning a language without learning vocabulary is impossible. Rivers expresses that it is not easy for primary students to gain a wide vocabulary because remembering vocabulary seems to be the biggest obstacle for them. In order to overcome this problem, a good teaching method is required. In this case, the realm of education has witnessed conflicting discussions on vocabulary teaching and learning. Zimmerman (1997), for example, argues that vocabulary teaching and learning has been undervalued in second language learning. Hedge (2000) makes it clear that although vocabulary teaching has been developing fast, it has not reached the level of consistency and systematicity that grammar has reached. Moreover, Sokmen (1997) admits that although most foreign language learners generally see vocabulary learning as their first priority, most L2 practitioners and textbook writers put their all effort on grammar but not vocabulary.

Paribakht and Wesche (1997) point out that an enormous amount of research should be conducted in the vocabulary field. As they suggest "it is still far from clear how learners acquire vocabulary or how it can best be taught" (p. 174). In the EFL context of Iran, where the present study was carried out, relevant previous studies reported that teachers in schools pay their highest attention to teaching grammar and neglect vocabulary and only they teach very few decontextualized words (e.g., Bahari, 1989; Mahmoodi, 1990). There is a consensus that the problem of teaching and 
learning English in Iran is related to the teaching methodology and inappropriate methods the English teachers use (see Asai, 1959; Dahmardeh, 2010; Noora, 2008).

There seems to be various methods for vocabulary teaching; however, Blachowicz (1986) believes that teaching vocabulary is a complex and complicated issue because there is not a definite method. According to Doff (1988), there are some techniques for vocabulary teaching in English. These techniques include guessing, using visual aids, eliciting word from picture, showing meaning, giving examples, and vocabulary expansion. Similarly, Lewis and Hill (1985) advise teachers to use various techniques or methods in vocabulary teaching such as meaning demonstration, using real things, drawing or sketching, using the board, using antonyms or synonyms, using dictionary, explaining new words verbally, translating, and teaching words in groups and hyponyms.

Current prevailing view is that students must notice what they learn. This noticing can best be obtained by input flooding which is the concern of the present study (see Schmitt, 2002). Gass (1997) states that a vocabulary item or language structure that is very frequent in the input will be more likely noticed by learners. Schmitt defines input flooding as increasing the number of times that learners face a word or structure in a specific text. In this regard, vocabulary flooding in this study is defined as increasing the number of times that learners face vocabulary items.

Some scholars (e.g., Krashen, 1985; Sokmen, 1997; Thornberry, 2002; Trahey \& White, 1993) speak about the desirability of input flood and its effectiveness for language learning. Hedge (2000) proposes that input flooding makes learning stable and forgetting improbable. Based on what Krashen (1985) says, rich comprehensible input and input flood are main prerequisites for learning a second language. In this regard, Kachroo (1962, as cited in Nation, 1990) researched the relationship between word frequency in a course book and learning of vocabulary and found that words with multiple repetitions were the most likely to be learned by language learners. Lado, Baldwin, and Lobo (1967) also carried out a similar study and presented their intermediate level college students of Spanish with a list of 100 words, and found that several exposures are enough for an average of $95 \%$ recognition and $65 \%$ recall.

Many researchers explain about the usefulness of input flood on the vocabulary learning of children or elementary learners. For instance, Zahar, Cobb, and Spada (2001), pointing to the inefficiency of learning vocabulary through extensive reading, assert that lower level learners need more encounters of words for learning to occur. Palmberg (1987) in his research study on beginning ESL students in Sweden found that learners are more likely to recall the words from their books, when they encounter words most often. Elley and Mangubhai (1981) in their famous "book flood" studies proved that elementary school children encountering words or input frequently are found to be successful in vocabulary gains. Likewise, other researchers (e.g., Coady, 1997; Mc knewn, Beck, Omanson, \& Perfetti,1983; Trahey \& White , 1993) indicate that one of the successful methods of vocabulary teaching/learning for children at the elementary level is repeated encounter of words in various contexts.

Not many researchers make clear how many words should exist in input flood technique. As Wong (2004) points out, no rule has been proposed for determining the optimal number of words in input flood. Table 1 presents the number of encounters or frequency of words needed for successful vocabulary learning that are suggested by different researchers for learners at mostly elementary and intermediate levels:

Table1. The Frequency of Words for Successful Learning Suggested by Different Researchers

\begin{tabular}{lcll}
\hline Researcher & Encounters (in number) & Researcher & Encounters (in words) \\
\hline Crothers and Suppes (1967) & $6-7$ & Brown (1993) & Frequent exposures \\
\hline Ghadirian (2002) & $5-20$ & Coady (1997) & Repeated exposures \\
\hline $\begin{array}{l}\text { Horst, Cobb, and Meara } \\
\text { (1998) }\end{array}$ & 8 or more & Cook (2001) & Several times \\
\hline Nagy and Scott(2000) & 3 & Elley and Mangubhai (1981) & Frequent encounters \\
\hline Nation(1990) & $5-16$ & Joe (2010) & Frequent encounters \\
\hline Nation and Wang (1999) & 10 & $\begin{array}{l}\text { Lado, Baldwin, and Lobo } \\
(1967)\end{array}$ & Several exposures \\
\hline Rott (1999) & 6 & Palmberg (1987) & Most often \\
\hline $\begin{array}{l}\text { Saragi, Nation, and Meister } \\
\text { (1978) }\end{array}$ & 6 or more & Sokmen (1997) & Abundant encounters \\
\hline Webb (2007) & & & \\
\hline The present study & 10 & Wesche and Paribakht (1994) & Many times \\
\hline
\end{tabular}

Sokmen (1997) also favors frequency of encounters in vocabulary learning and he explains that, in a review of current trends in second language vocabulary teaching, providing abundant encounters with new words increases the possibility that the word will be learned. Cook (2001) confesses the value and importance of meeting a word for several times to learn and easily remember it. Joe (2010) in a research study in New Zealand found that frequency of encounters contributes more to vocabulary learning than contextual richness does. Some other researchers indicate that flooding exposure to words in short term periods are preferable and lead to learning (e.g., Baddeley, 1990; Dempster, 1987; Laufer \& Osimo, 1991; Mondria \& Mondria-de Vries, 1994). There are also many studies that introduce vocabulary learning from frequent exposures to words as an appropriate method of vocabulary learning (see Beck, Perfetti, \& McKeown, 1982; Brown, 1993; Krashen, 1989; Nagy, Herman, \& Anderson, 1985; Rott, 1999).

However, to the knowledge of the researchers, there was not any study regarding input flood in terms of vocabulary in the EFL context of Iran. In this regard, the aim of the present study was to find out the effect of vocabulary flooding 
compared to the no vocabulary flooding techniques on Iranian EFL elementary learners' vocabulary learning at the recognition level. For this, the following null hypotheses were formulated:

$\mathrm{H}_{01}$. There is no significant difference in the mean scores of the vocabulary flooding group in the vocabulary recognition pretest, immediate posttest, and delayed posttest.

$\mathrm{H}_{02}$. There is no significant difference in the mean scores of the no vocabulary flooding group in the vocabulary recognition pretest, immediate posttest, and delayed posttest.

$\mathrm{H}_{03}$. There is no significant difference in the mean scores of the vocabulary flooding and the no vocabulary flooding groups in the vocabulary recognition pretest, immediate posttest, and delayed posttest.

\section{Method}

\subsection{Design}

This study was a quasi-experimental research with a pretest-posttest control group design. Vocabulary flooding technique was the independent variable and vocabulary learning at the recognition level was the dependent variable of the study. In this study, vocabulary flooding technique was manipulated as the treatment in one of the intact groups of the study.

\subsection{Participants}

This study was conducted at a lower secondary school (equivalent to US Middle school), in the new city of Sahand near Tabriz in East-Azarbijan, Iran, in the first semester of the academic year 2012-2013. All of the participants in the research were male students because the school was only for males. They were 14-15 years of age and in the third grade. In Iran, students formally start learning English as a foreign language (as one of their school subjects) at the lower secondary school (known as guidance school) for three years. After that, they continue their English learning at the upper secondary school for another three years. In the school in which this study was conducted, there were four third-grade classes. At the beginning of the semester, a KET test was administered in order to select the homogenous participants. Based on the results, the researchers selected two classes (a and b) as homogenous ones for the study. Then, these classes were randomly assigned into the experimental (vocabulary flooding) and control (no vocabulary flooding) groups, each with 30 students.

\subsection{Instruments and Materials}

\subsubsection{Testing instruments}

\section{a) KET Test}

The Cambridge Key English Test (KET) is a standard proficiency test which is used for elementary learners. The Key English Test is the easiest of the Cambridge exams. Because of the practicality problems, the listening and speaking sections were excluded from this proficiency test and only the reading and writing sections of the KET were administered.

b) Pre-test and Post-test

A twenty-item vocabulary recognition test consisting of multiple-choice items was administered to the both groups. This twenty item test was adopted from the vocabulary items which were taught in the supplementary vocabulary activity of both groups. The test was checked for content validity by three English teachers to make sure that they were appropriate. The posttest (which was similar to the pre-test) was administered twice: once immediately after the treatment, and once, a month after the treatment. The reliability of the pretest and posttests was checked through Cronbach's Alpha and a high internal reliability was obtained for the pretest $(\alpha=.82)$, immediate posttest $(\alpha=.90)$, and delayed posttest $(\alpha=.91)$ of vocabulary recognition, respectively.

\subsubsection{Teaching materials}

a) English textbook

The English language textbook "Right path to English" (Birjandi \& Soheili, 2009), which is used for the third-grade students in the secondary schools in Iran, is mostly based on vocabulary and grammar. The new words used in this study were the new words of the first three lessons in this textbook.

b) Supplementary vocabulary activity

A supplementary vocabulary activity was also used in both groups. For the no vocabulary flooding group, the supplementary activity included only one sentence for each new word while for the vocabulary flooding group, it included several sentences in which each new word was repeated six or more times in these sentences.

\subsection{Procedure}

Four intact classes of third-grade students were in the secondary school where this study was conducted. A KET test was given to these classes, and according to the results of the KET, two classes were excluded. The other two were randomly assigned into the vocabulary flooding (experimental) and no vocabulary flooding (control) groups. One of the researchers was the English teacher of both groups. The students at the third grade have two sessions of one and a half hour English classes every week. They study English from the first year of secondary school.

The researchers selected 50 new words from the first three lessons in the student's textbook "Right path to English". Before presenting the new words, the teacher used a checklist in both groups to make sure that these words were unknown for the participants. The participants indicated their knowledge of the words by choosing one of the two 
options: 'I know the word' or 'I don't know the word'. Besides, in order to get a realistic result, the students had to write the meaning of the word if they choose the 'I know the word' option in the checklist. The words that students knew were deleted in this study. For example, the words 'restaurant', and 'zoo' were omitted because a majority of the participants knew these words. A pretest based on the unknown words was given to the both groups. The pretest consisted of recognition questions in the form of 20 multiple-choice items. The allocated time was 15 minutes for both groups. Followings are sample questions from the pretest:

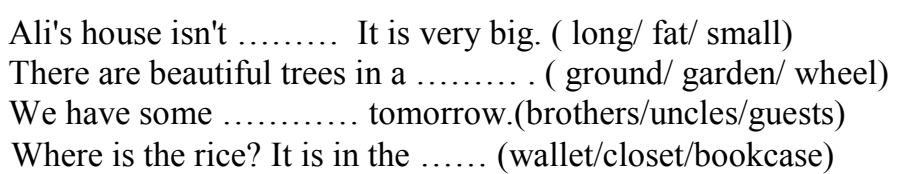

After the pretest, the treatment was manipulated. In the both experimental and control groups, first the new words were taught traditionally. In other words, the students listened and repeated the new words and the teacher presented the meaning of the new words. Then, the supplementary vocabulary activities were used in both groups. For the no vocabulary flooding group, the supplementary activity included only one sentence for each new word. It was given to them as a placebo on a piece of paper. For the vocabulary flooding group, the supplementary activity included several sentences for each new word. Each new word was used several times in these sentences in a flooding form. For presenting the supplementary activity in both groups, first the teacher read the sentences of supplementary activity aloud to avoid any potential pronunciation difficulties. For the second time, the teacher asked the students to read the sentences by themselves. Some of the sentences of the supplementary activities were selected from Oxford Advanced Learners dictionary and Longman Dictionary of Contemporary English. For this, the sentences that had the required vocabulary and were appropriate for learners' level were selected.

In order to check whether these sentences were appropriate for the third grades or not, the teacher asked other English language teachers working in the same school to check the difficulty level of the sentences. Based on their comments, some sentences were revised. After eight sessions of treatment in four weeks, including two sessions in a week, a posttest similar to the pretest was conducted for the both groups and after one month from the treatment, a delayed posttest similar to the pretest and immediate posttest was also given to the both groups. The collected data were entered into the SPSS 17 for further analysis. The normality test of Kolmogorove-Smirnov for pretest, posttest, and delayed posttest of vocabulary recognition was run and the results showed no violation of the assumption. This implied that the scores in all tests of this study were normally distributed, which made the use of parametric tests feasible. Therefore, in order to test the first and second null hypotheses, a one-way within-subjects repeated measures ANOVA was carried out and to test the third null hypothesis a one-way between-subjects repeated measures ANOVA was run.

\section{Results}

\subsection{Results of the Proficiency Test}

A KET test was given to the four third-grade classes. A one-way ANOVA was carried out to find out whether there was a significant difference among the KET scores of the four classes. The results indicated a statistically significant difference, $F(3,116)=2.426, p=.045$, among the mean scores of the four classes. Therefore, multiple comparisons were conducted to find the classes whose means were significantly different. Table 2 shows the descriptive statistics such as means and standard deviations and the results of the multiple comparisons including mean difference, significant value, and $95 \%$ confidence interval for the scores of the four classes (a, b, c, d).

Table 2. Descriptive Statistics and Multiple Comparisons of the Four Classes

\begin{tabular}{|c|c|c|c|c|c|c|}
\hline Class $r$ & & $M$ & $S D$ & $M D$ & $p$ & $95 \% \mathrm{CI}$ \\
\hline $\mathrm{a}$ & 30 & 13.50 & 9.61 & & & \\
\hline $\mathrm{b}$ & 30 & 13.76 & 9.12 & & & \\
\hline $\mathrm{c}$ & 30 & 7.96 & 9.06 & & & \\
\hline d & 30 & 13.00 & 10.73 & & & \\
\hline$a-b$ & & & & -0.26 & .915 & {$[-5.21,4.67]$} \\
\hline$a-c$ & & & & 5.54 & $.028^{*}$ & {$[0.59,10.47]$} \\
\hline$a-d$ & & & & 0.50 & .841 & {$[-4.44,5.44]$} \\
\hline$b-c$ & & & & 5.80 & $.022^{*}$ & {$[0.86,10.74]$} \\
\hline b-d & & & & 0.77 & .759 & {$[-4.17,5.71]$} \\
\hline$c-d$ & & & & -5.03 & $.046^{*}$ & {$[-9.97,-0.09]$} \\
\hline
\end{tabular}

Note. ${ }^{*} p<.05$

As shown in Table 2, the means of the classes a-c, b-c, and c-d were significantly different. However, as Table 2 indicates, the mean scores of classes a and $\mathrm{b}$ were closer to each other compared to class $\mathrm{d}$. Therefore, the classes a and $\mathrm{b}$ were selected as the two homogeneous groups of the study.

3.2 Results of the Data Analysis for $\mathrm{H}_{01}$ and $\mathrm{H}_{02}$

In order to test the first and second Null hypotheses, a one way within-subjects Repeated Measures ANOVA was conducted. Table 3 shows the means, standard deviations, and standard errors in the pretest, immediate posttest, and 
delayed posttest of vocabulary recognition for the experimental (vocabulary flooding group) and the control (no vocabulary flooding group) groups.

Table 3. Descriptive Statistics for the Recognition Test in the Vocabulary Flooding and No Vocabulary Flooding Groups

\begin{tabular}{|c|c|c|c|c|c|c|}
\hline \multirow{2}{*}{ Recognition } & \multicolumn{3}{|c|}{ Experimental } & \multicolumn{3}{|c|}{ Control } \\
\hline & $\mathrm{M}$ & $\mathrm{SD}$ & $\mathrm{SE}$ & $\mathrm{M}$ & $\mathrm{SD}$ & SE \\
\hline Pretest & 2.43 & 3.25 & .59 & 3.86 & 3.50 & .64 \\
\hline Posttest & 15.53 & 3.52 & .64 & 9.73 & 5.09 & .93 \\
\hline Delayed posttest & 15.60 & 4.08 & .74 & 9.46 & 6.07 & 1.11 \\
\hline
\end{tabular}

The assumption of sphericity was also checked for this analysis in both groups. The results showed a violation of sphericity in the experimental, Mauchly's W (2) $=.236, p=.000$, and control, Mauchly's W $(2)=.282, p=.000$, groups, respectively. Therefore, in order to find whether there was a statistically significant difference among the three recognition tests, in the test of within-subjects effects the values for the Greenhouse-Geisser (Leech, Barrette, \& Morgan, 2005) were considered. The results revealed that the means of the three recognition tests were significantly different in both the experimental group, $F(1.134,32.872)=206.029, P=.000$, Partial Eta squared $=.88$, and the control group, $F(1.164,33.752)=23.474, P=.000$, Partial Eta squared $=.45$. Compared to the Cohen's (1988) criteria $(.01=$ small, $.06=$ medium, $.14=$ large $)$, the partial Eta squared in both groups indicated a very large effect size for the difference among the three recognition tests. In order to determine the mean scores of the tests that were significantly different from the others, pairwise comparisons were executed for the both groups. The results are shown in Table 4.

Table 4. Pairwise Comparisons for the Three Recognition Tests in the Vocabulary Flooding (Experimental) and No Vocabulary Flooding (Control) Groups

\begin{tabular}{|c|c|c|c|c|c|c|c|}
\hline \multirow[b]{2}{*}{ Group } & \multirow[b]{2}{*}{ (I) TestR } & \multirow[b]{2}{*}{ (J) TestR } & \multirow{2}{*}{$\begin{array}{c}\text { Mean Difference } \\
(\mathrm{I}-\mathrm{J})\end{array}$} & \multirow[b]{2}{*}{ Std. Error } & \multirow[b]{2}{*}{ Sig. } & \multicolumn{2}{|c|}{$\begin{array}{l}\text { 95\% Confidence Interval for } \\
\text { Difference }\end{array}$} \\
\hline & & & & & & Lower Bound & Upper Bound \\
\hline \multirow[t]{6}{*}{ Experimental } & 1 & 2 & $-13.100^{*}$ & .850 & .000 & -14.839 & -11.361 \\
\hline & & 3 & $-13.167^{*}$ & .935 & .000 & -15.078 & -11.255 \\
\hline & 2 & 1 & $13.100^{*}$ & .850 & .000 & 11.361 & 14.839 \\
\hline & & 3 & -.067 & .279 & .813 & -.638 & .505 \\
\hline & 3 & 1 & $13.167^{*}$ & .935 & .000 & 11.255 & 15.078 \\
\hline & & 2 & .067 & .279 & .813 & -.505 & .638 \\
\hline \multirow[t]{6}{*}{ Control } & 1 & 2 & $-5.867^{*}$ & 1.113 & .000 & -8.143 & -3.591 \\
\hline & & 3 & $-5.600^{*}$ & 1.191 & .000 & -8.035 & -3.165 \\
\hline & 2 & 1 & $5.867^{*}$ & 1.113 & .000 & 3.591 & 8.143 \\
\hline & & 3 & .267 & .386 & .496 & -.524 & 1.057 \\
\hline & 3 & 1 & $5.600^{*}$ & 1.191 & .000 & 3.165 & 8.035 \\
\hline & & 2 & -.267 & .386 & .496 & -1.057 & .524 \\
\hline
\end{tabular}

Note. TestR= Recognition Test, $1=$ pretest, $2=$ immediate posttest, $3=$ delayed posttest; $* \mathrm{p}<.05$

As Table 4 demonstrates, in the vocabulary flooding group, there was a significant mean difference between the pretest $(M=2.43, S E=.59)$ and immediate posttest $(M=15.53, S E=.64)$ scores, implying that the immediate posttest mean score was significantly higher than the pretest. The results also indicated a significant mean difference between the pretest and delayed posttest $(M=15.60, S E=.74)$ scores. There was not any significant difference in the mean scores of the immediate posttest and delayed posttest in this group. Therefore, the first null hypothesis, that is, there is no significant difference in the mean scores of the vocabulary flooding group in the vocabulary recognition pretest, immediate posttest, and delayed posttest, was rejected. In other words, input flooding technique had a significant effect on the vocabulary learning of the vocabulary flooding group after the treatment period.

Considering the control group, as seen in Table 4, there was a significant mean difference between the pretest $(M=$ $3.86, S E=.64)$ and immediate posttest $(M=9.73, S E=.93)$ scores, implying that the immediate posttest mean score was significantly higher than the pretest. The results also indicated a significant mean difference between the pretest and delayed posttest $(M=9.46, S E=1.11)$ scores. There was not any significant difference in the mean scores of the immediate posttest and delayed posttest in the no vocabulary flooding group. Therefore, the second null hypothesis, that 
is, there is no significant difference in the mean scores of the no vocabulary flooding group in the vocabulary recognition pretest, immediate posttest, and delayed posttest, was also rejected.

\subsection{Results of the Data Analysis for $\mathrm{H}_{03}$}

In order to test the third Null hypothesis, the researchers conducted a one-way between-subjects Repeated Measures ANOVA. The assumption of sphericity was not met, Mauchly's W $(2)=.265, p=.000$. For this reason, in the test of within- subjects effects (see Table 5), the values in the Greenhouse-Geisser row were considered for the trial main effects (factor 1) and the interaction effects (Factor 1 by Group).

Table 5. Test of Within-Subjects Effects

\begin{tabular}{|c|c|c|c|c|c|c|}
\hline Source & & $\begin{array}{c}\text { Type III Sum } \\
\text { of Squares }\end{array}$ & df & Mean Square & $\mathrm{F}$ & Sig. \\
\hline \multirow[t]{4}{*}{ FACTOR1 } & Sphericity Assumed & 3559.811 & 2 & 1779.906 & 158.934 & .000 \\
\hline & Greenhouse-Geisser & 3559.811 & 1.153 & 3088.209 & 158.934 & .000 \\
\hline & Huynh-Feldt & 3559.811 & 1.181 & 3013.069 & 158.934 & .000 \\
\hline & Lower-bound & 3559.811 & 1.000 & 3559.811 & 158.934 & .000 \\
\hline \multirow[t]{4}{*}{ FACTOR1 $*$ GROUP } & Sphericity Assumed & 548.433 & 2 & 274.217 & 24.486 & .000 \\
\hline & Greenhouse-Geisser & 548.433 & 1.153 & 475.777 & 24.486 & .000 \\
\hline & Huynh-Feldt & 548.433 & 1.181 & 464.201 & 24.486 & .000 \\
\hline & Lower-bound & 548.433 & 1.000 & 548.433 & 24.486 & .000 \\
\hline \multirow[t]{4}{*}{ Error(FACTOR1) } & Sphericity Assumed & 1299.089 & 116 & 11.199 & & \\
\hline & Greenhouse-Geisser & 1299.089 & 66.857 & 19.431 & & \\
\hline & Huynh-Feldt & 1299.089 & 68.525 & 18.958 & & \\
\hline & Lower-bound & 1299.089 & 58.000 & 22.398 & & \\
\hline
\end{tabular}

As Table 5 indicates, there was a significant main effect of three recognition tests (Factor 1$), F(1.153,66.857)=$ $158.934, P=.000$, and a significant interaction effect of three tests by group, $F(1.153,66.857)=24.486, P=.000$. Based on the test of between-subjects effects, a significant group difference, $F(1,58)=15.752, P=.000$, was also found (see Table 6).

Table 6. Test of Between Subjects-Effects

\begin{tabular}{lccccc}
\hline Source & $\begin{array}{c}\text { Type III Sum of } \\
\text { Squares }\end{array}$ & df & Mean Square & F & Sig. \\
\hline Intercept & 16036.672 & 1 & 16036.672 & 458.248 & .000 \\
GROUP & 551.250 & 1 & 551.250 & 15.752 & .000 \\
Error & 2029.744 & 58 & 34.996 & & \\
\hline
\end{tabular}

The group differences in three recognition tests can also be seen, clearly, in the Figure 1 ( $1=$ pretest, $2=$ immediate posttest, $3=$ delayed posttest). 


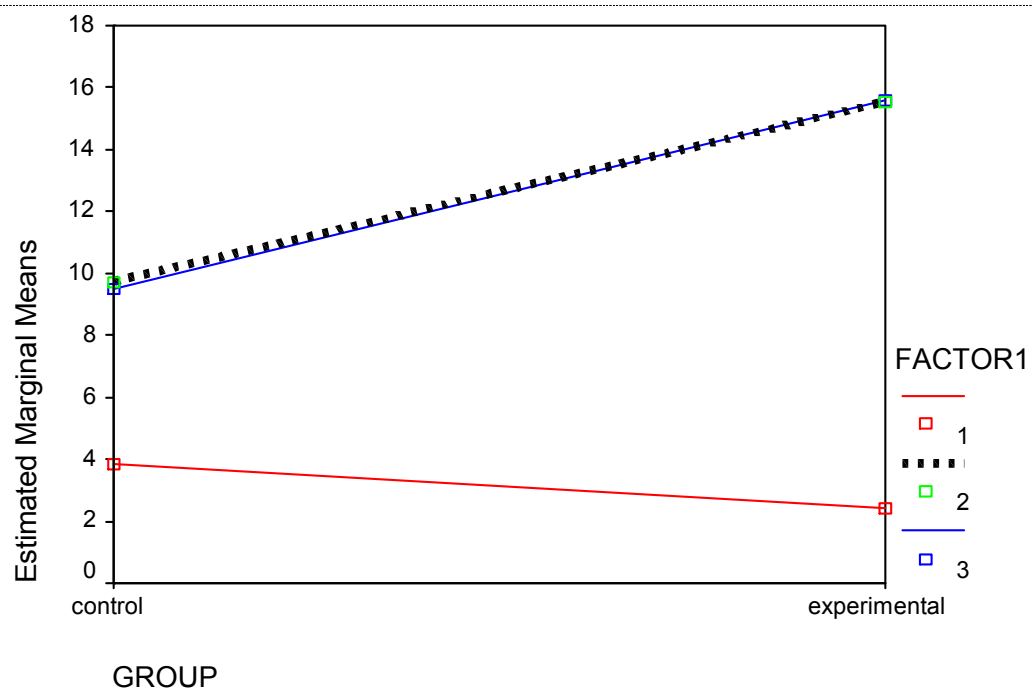

Figure1. Estimated Marginal Means for Three Recognition Tests in The Vocabulary Flooding and the No Vocabulary Flooding Groups

In summary, the results indicated that the mean scores in the immediate and delayed recognition posttests were higher in the vocabulary flooding group compared to the no vocabulary flooding group. Therefore, based on the results, the third null hypothesis, that is, there is no significant difference in the mean scores of the vocabulary flooding and the no vocabulary flooding groups in the vocabulary recognition pretest, immediate posttest, and delayed posttest, was rejected. This indicates the higher effect of vocabulary flooding technique on the vocabulary learning of the participants in this study.

\section{Discussion}

The main goal of this study was to find out the effect of using vocabulary flooding technique on Iranian EFL elementary learners' vocabulary learning. The results indicated that there was a positive effect of vocabulary flooding on the vocabulary learning of the participants at the recognition level. The results also revealed that although the control or no vocabulary flooding group, which had one encounter for each new word, showed improvement in the immediate and delayed posttests of vocabulary recognition, the experimental or vocabulary flooding group outperformed the control group. Compared to the pretest, the experimental group, with several encounters of each new word, had significantly higher improvement in the immediate and delayed vocabulary recognition posttests. This shows the important role of vocabulary flooding technique on the vocabulary learning of the students after the experiment. There was not a significant difference in the results of the immediate and delayed posttests. This reveals that the flooding technique can also be effective for a longer period of time.

In line with the results of this study, some scholars have highlighted the role of vocabulary flooding technique in learner's vocabulary learning; for example, Trahey and White (1993) pointed out that vocabulary flooding is effective for learning vocabulary items. Kachroo (1962, as cited in Nation, 1990) also made clear that words with multiple repetitions are more probable to be learned by language learners. The result of this study is in agreement with other researchers' studies (e.g., Ellis \& Sinclair, 1996; Horst, Cobb, \& Meara, 1998) that were conducted in EFL settings. These researchers found that repeated encounter of words help learners to learn vocabulary and remember them later. Something that causes the learners forget the words is that they store them in memory and seldom encounter, review, or use them, so encountering or using words in different contexts play an important role in remembering them (Hedge, 2000; Richards \& Renandya, 2002). In this study, like the previous studies carried out by Coady (1997) and Elley and Mangubhai (1981), the focus was on elementary level, but in some other studies (e.g., Plamberg, 1979; Rott, 1999; Wesche \&Paribakht, 1994), other proficiency levels including beginner and intermediate were considered. However, in all of these studies vocabulary flooding technique was found beneficiary for vocabulary learning at all levels especially at lower levels (Zahar, Cobb, \& Spada, 2001).

As Wong (2004) states, so far there is no rule to determine how many words are optimal for input flood. Nation (1990) suggested exposures of 5 to 16 for learning a word from the context. All the studies with the encounters of six or more seem to succeed. In the present study, like the studies conducted by Saragi, Nation, and Meister (1978) and Crothers and Suppes (1967), six or seven encounters were used. In the study by Horst, Cobb, and Meara (1998), the learners were exposed to each new word eight times and in Webb's (2007) study ten encounters were reported. The results of these studies imply that the better acquisition of a new word is related to the number of times a word is encountered by the student. This means that several introduction of a new word in a lesson or different sections of a textbook provides a cyclical encounter with the word and helps the student keep the word in the long term memory.

\section{Conclusion}

From the results of this study, it can be concluded that, as Zahar, Cobb, and Spada (2001), in a study on incidental reading, state, vocabulary acquisition is a function of frequency. Therefore, the results of this study in the EFL situation of Iran verify the results of the previous studies conducted to show the significant effect of input flood on the 
vocabulary learning of the students. This study reflects the importance of vocabulary flooding on the vocabulary recognition of the learners in the EFL context.

Based on the findings of the study, it can be concluded that applying vocabulary flooding technique can help teachers to increase the effectiveness of their teaching, which in turn can increase learners' vocabulary knowledge at the recognition level. Thus, it is for the syllabus designers and material writers to consider the recycling aspect of new words in different parts of the textbooks. In other words, the students should be provided with "repeated opportunities to meet and enrich important items" (Nation \& Macalister, 2010, p.83). The present study was conducted among the elementary EFL learners and the aim was to find out the effect of frequent encountering of words on their vocabulary recognition. Further research can be conducted to examine the impact of vocabulary flooding on the elementary learners' vocabulary learning at the production level. More research is needed to determine the number of encounters needed to recognize or produce the learnt vocabulary at the elementary, intermediate, or advanced levels. It is because, as Nation and Wang (1999) indicate, learning words does not guarantee the acquisition of them for future use.

\section{References}

Asai, F. (1959). Amoozesh-e zaban dar iran, Language teaching in Iran. Mahnameh-e amoozesh va parvaresh, 4, 70-81.

Baddeley, A. (1990). Human memory: Theory and practice. London: Lawrence Erlbaum Associates.

Bahari, M. (1989). Moonlighting among Iranian teachers. United States: Arizona State University.

Beck, I. L., Perfetti, C. A., \& McKeown, M. G. (1982). The effects of long-term vocabulary instruction on lexical access and reading comprehension. Journal of EducationalPsychology, 74, 506-521.

Birjandi, P. \& Soheili, A. (2009). Englisi sevom Rahnomaee, English for grade three secondary school. Tehran: Iranian school book publication and printing company.

Blachowicz, C. (1986).Making connections: Journal of Reading, 29,643-649.

Brown, C. (1993). Factors affecting the acquisition of vocabulary. In T. Huckin, M. Haynes, \& J. Coady (Eds.), Second language reading and vocabulary (pp. 263-286). Norwood, NJ: Ablex.

Coady, J. (1997). L2 vocabulary acquisition: A synthesis of the research. In J. Coady \& T. Huckin (Eds.), Second language vocabulary acquisition (pp. 273-290). Cambridge: Cambridge University Press.

Cohen, J. W. (1988). Statistical power analysis for the behavioral sciences. Hillsdale, NJ: Erlbaum.

Cook, V. (2001). Second Language Learning and Language Teaching. London: Hodder Education.

Crothers, E., \& Suppes, P. (1967). Experiments in second-language learning. New York: Academic Press.

Dahmardeh, M. (2010). Communicative Textbooks. Linguistic online, 40, 4-9.

Decarrio , J. S. (2001). Vocabulary learning and teaching. In M. Celce-Murcia, Teaching: English as a second or foreign language (pp. 285-299). Boston: Heinle and Heinle.

Dempster, F. N. (1987). Effects of variable encoding and spaced presentation on vocabulary learning. Journal of Educational Psychology, 79, 162-170.

Doff, A. (1988). Teach English: A trainer's handbook. Cambridge: Cambridge University Press.

Ellis, N., \& Sinclair, S. (1996). Working memory in the acquisition of vocabulary and syntax: Putting language in good order. The Quarterly Journal of Experimental Psychology, 49, 234-250.

Elley, W. B., \& Mangubhai, F. (1981). The impact of a book flood in Fiji primary schools. Wellington: New Zealand Council for Educational Research.

Ghadirian, S. (2002). Providing controlled exposure to target vocabulary through the screening and arranging of texts. Language, Learning \& Technology, 6 (1), 147-164.

Gass, S. (1997). Input, interaction, and the second language learner. Mahwah, NJ. : Lawrence Erlbaum.

Hedge, T. (2000). Teaching and learning in the language classroom. Oxford: Oxford University Press.

Horst, M., Cobb, T., \& Meara, P. (1998). Beyond a clockwork orange: Acquiring second language vocabulary through reading. Reading in a Foreign Language, 11(2), 207-223.

Joe, A. (2010). The quality and frequency of encounters with vocabulary in English for Academic Purposes programme. Reading in a Foreign Language, 22, 117-138.

Krashen, S. (1985). The Input Hypothesis. London: Longman.

Krashen, S. (1989). We acquire vocabulary and spelling by reading: Additional evidence for the input hypothesis. The Modern Language Journal, 73, 440-464.

Lado, R., Baldwin, B., \& Lobo, F. (1967). Massive vocabulary expansion in a foreign language beyond the basic course: The effects of stimuli, timing and order of presentation. Washington, D.C.: Department of Health, Education, and Welfare. 
Laufer, B., \& Osimo, H. (1991). Facilitating long-term retention of vocabulary: The second-hand cloze. System, 19, 217-224.

Leech, N.L., Barrette, K.C., \& Morgan, G. A. (2005). SPSS for Intermediate statistics: use and interpretation ( ${ }^{\text {nd }}$ ed.). Mahwah, New Jersey: Lawrence Erlbaum Associates, Inc.

Lewis, M., \& Hill, J. (1985). Practical Techniques for Language Teaching. London: Language Teaching Publications.

Mahmoodi, G. (1990). Analysis of English language teaching problems and failure in the Educational System. Roshd Language Teaching Journal, 22, 13-19.

McKeown, M. G., Beck I. L., Omanson, R., \& Perfetti, C. A. (1983). The effects of long-term vocabulary instruction on reading comprehension: A replication. Journal of Reading Behavior, 15, 3-18.

Mondria, J. A., \& Mondria-de Vries, S. (1994). Efficiently memorizing words with the help of word cards and "hand computer": Theory and applications. System, 22, 47-57.

Nagy, W., Herman, P., \& Anderson, R. (1985). Learning words from context. Reading Research Quarterly, 20, 233253.

Nagy, W., \& Scott, J. (2000). Vocabulary processes. In M. L. Kamil, P. B. Mosenthal, P. D. Pearson, \& R. Barr (Eds.), Handbook of Reading Research, Volume III (pp. 269-284). Mahwah, NJ: Lawrence Erlbaum.

Nation, I. S. P. (1990). Teaching and Learning Vocabulary. New York: Newbury.

Nation, I. S. P., \& Macalister, J. (2010). Language curriculum design. New York: Routledge.

Nation, I. S. P., \& Wang, M. K. (1999). Graded readers and vocabulary. Reading in a Foreign Language, 12, 355-379.

Noora, A. (2008). Iranian Undergraduates Non-English Majors' Language Learning Islamic Azad University of Dehaghan. Online Journal of Language Studies, 33, 8-12.

Palmberg, R. (1987). Patterns of vocabulary development in foreign-language learners. Studies in Second Language Acquisition, 9(2), 201-219.

Paribakht, T., \& Wesche, M. (1997). Vocabulary enhancement activities and reading for meaning in second language vocabulary acquisition. In J. Coady \& T. Huckin (Eds.), Second Language Vocabulary Acquisition (pp. 68-75). Cambridge: Cambridge University Press.

Richards, J. C., \& Renandya, W. A. (2002). Methodology in Language Teaching. An Anthology of Current Practice. New York: Cambridge University Press.

Rivers, W. M. (1981). Teaching foreign language skills. Chicago : University of Chicago.

Rott, S. (1999). The effect of exposure frequency on intermediate language learners' incidental vocabulary acquisition and retention through reading. Studies in Second Language Acquisition, 21, 589-620.

Saragi, T., Nation, I. S. P., \& Meister, A. (1978). Vocabulary learning and reading. System, 6, 70-78.

Schmitt, N. (2002). Applied Linguistics. London: Oxford University Press.

Sokmen, A. J. (1997). Current trends in teaching second language vocabulary. In N. Schmitt \& M. McCarthy (Eds.), Vocabulary: Description, Acquisition and Pedagogy (pp. 237- 257). Cambridge: Cambridge University Press.

Thornbury, S. (2002). How to teach Vocabulary. London: Longman.

Trahey, M., \& White, L. (1993). Positive evidence and preemption in the second language classroom. Studies in Second Language Acquisition, 5, 181-204.

Webb, S. (2007). The effects of repetition on vocabulary knowledge. Applied Linguistics, 28, 46-65.

Wesche, M., \& Paribakht, T. (1994). Enhancing Vocabulary Acquisition Through Reading: A Hierarchy of Text-related Exercise Types. Paper presented at the meeting of the American Association for Applied Linguistics (AAAL), Baltimore, MD.

Wong, W. (2004). Processing instruction in French: The roles of explicit information and structured input. In B. Van Patten (Ed.), Processing instruction: Theory, research, and commentary (pp. 187-205). Mahwah, NJ: Lawrence Erlbaum Associates.

Xanthou, M. (2010). Current trends in L2 vocabulary learning and instruction: Is CLIL the right approach? Advances in Research on Language Acquisition and Teaching: Selected Papers, 21, 459-471.

Zahar, R., Cobb, T., \& Spada, N. (2001). Acquiring vocabulary through reading: Effects of frequency and contextual richness. The Canadian Modern Language Review, 57, 541-572.

Zimmerman, C. B. (1997). Historical trends in second language vocabulary instruction. In J. Coady \& T. Huckin (Eds.), Second Language Vocabulary Acquisition. Cambridge: Cambridge University Press. 